\title{
On the Role of Mental Health Activities for Teachers' Work and Life
}

\author{
Hanna Hofmann ${ }^{1}$ (D) D Daniel Groß ${ }^{1} \cdot$ Carl-Walter Kohlmann $^{1}$
}

Published online: 24 November 2020

(C) The Author(s) 2020

\begin{abstract}
Everyday behavior is getting increasingly attention, both in the prevention of mental impairment and the promotion of mental health - within and beyond the work context. The present study aimed to identify the importance of mental health activities for wellbeing and positive functioning of teachers, while taking affectivity into account. Teachers are confronted with various stressors, and identifying predictors of teachers' well-being and positive functioning is important, not only for teachers' personal health, but also for their students' well-being and achievement. Based on the Broaden and Build (B\&B) theory and Conservation of Resources (COR) theory, we assumed that (1) the practice of mental health activities is associated with well-being (i.e., positive mental health) and positive functioning (i.e., healthy and unhealthy work-related behavior and experiences), and that (2) mental health activities mediate the association between affectivity and the respective outcomes. These assumptions were tested in a sample of 326 German teachers (75\% female, age: $M=44, S D=11.85$ ). The practice of mental health activities was associated with more positive mental health, more healthy work-related behavior and experiences, and less unhealthy work-related behavior and experiences. Moreover, mental health activities partly explained the relationship between affectivity and the respective outcomes. The present findings indicate the potential of mental health activities for mental health promotion in teachers but future studies are recommended in order to establish causal effects.
\end{abstract}

Keywords Teachers $\cdot$ Behavior $\cdot$ Work $\cdot$ Mediation analyses $\cdot$ Mental health $\cdot$ Activity Affectivity

Hanna Hofmann

hanna.hofmann@ph-gmuend.de

1 Department of Health Psychology, University of Education Schwäbisch Gmünd, Oberbettringer Str. 200, 73525 Schwäbisch Gmünd, Germany 


\section{Introduction}

Behavior has been recognized as a key mechanism to reduce mental impairment, to cope with work-related stressors, and to promote positive mental health and well-being (Jorm 2012; Kazdin and Rabbitt 2013; Layous et al. 2014; Sonnentag and Fritz 2007; Walsh 2011). Consequently, various suggestions for suitable and easy-to-implement activities were made, either with the aim to improve subjective well-being and happiness (e.g., Caunt et al. 2013; Tkach and Lyubomirsky 2006; Warner and Vroman 2011) or to reduce mental burdens (Morgan and Jorm 2009). There is increasing awareness on the usefulness of strategies to increase teachers' mental health and well-being (e.g., Falecki and Mann 2020) and the call to identify adequate leisure time experiences (Grund et al. 2016). However, the importance of universal and easy applicable recommendations for teachers' work and life is still unclear. In order to combine research of pathogenesis with salutogenesis (Keyes 2006), the first objective of the present study is to determine the relevance of identified activities to reduce mental stress (i.e., mental health activities) for promoting teachers' well-being and positive functioning.

Furthermore, previous research stressed the relevance of everyday activities as important mediators between dispositions and desired outcomes (Diener et al. 1999; Lyubomirsky et al. 2005; Tkach and Lyubomirsky 2006; Warner and Vroman 2011). Positive and negative affectivity are important dispositions that predict positive outcomes in work and life in general (Lyubomirsky et al. 2005; Ng and Sorensen 2009; Pressman and Cohen 2005) and teachers' work-related behavior and experiences in particular (Hofmann and Kohlmann 2019b). Hence, the second aim of the present study is to identify the extent to which mental health activities function as mediators between affectivity and teacher's well-being and positive functioning. As a theoretical framework, we include the Broaden and Build (B\&B) theory of positive emotions (Fredrickson 2004) and the Conservation of Resources (COR) theory (Hobfoll 1989, 2002). We will describe the assumed associations with the respective variables in more detail below.

\section{Teachers' Well-Being and Positive Functioning}

The teaching profession is related to various environmental challenges and potential stressors (Montgomery and Rupp 2005). For example, teachers face incompletely regulated working hours, infinite teaching tasks (no clear standard when a specific lesson plan is good enough), and the division of the workplace between school and home. Moreover, the teaching profession is associated with low levels of control in regard to effects achieved, no career possibilities, and a lack of feedback on the longterm consequences of teaching at school (Rothland 2013). Beyond teaching lessons, the teaching profession requires the preparation, planning, and assessment of teaching lessons as well as administrative tasks and meeting with parents (Philipp and Kunter 2013). Consequently, teachers often work more than the usual $40 \mathrm{~h}$ per week (Bauer et al. 2007). In line with that, teachers, as compared to other occupations, often show unhealthy work-related behavior and experiences (Schaarschmidt and Fischer 2008), characterized by a lack of coping abilities and negative emotions in regard to work. These unhealthy work-related behavior and experiences can impact not only teachers' mental and physical health (Bauer et al. 2006), but also students' motivation (Klusmann et al. 2008) and achievement (Klusmann et al. 2016). 
Although research focused largely on teacher stress and burnout, the importance of teacher well-being is getting more and more attention (e.g., Hwang et al. 2017; Klusmann et al. 2008; Mansfield 2020; Spilt et al. 2011). Despite various challenges in the teaching profession, a considerable amount of teachers is satisfied with their jobs (Gehrmann 2013; Schult et al. 2014) and there are teachers who are highly engaged, have sufficient coping abilities, and experience positive emotions (Schaarschmidt and Fischer 2008). These healthy work-related behavior and experiences are not only associated with improved occupational well-being for teachers but also with more competence and autonomy reported by their students (Klusmann et al. 2008). Furthermore, higher values of teachers' positive mental health are associated with higher scores for their students' well-being (Harding et al. 2019). Hence, identifying predictors of teachers' well-being and positive functioning is not only beneficial for teachers but also for their students.

Earlier research highlighted various resilience factors for teachers and differentiated between personal resources (e.g., sense of purpose, efficacy), contextual resources (e.g., autonomy, family support), and strategies to maintain and enhance occupational wellbeing and positive functioning (e.g., work-life balance, mindfulness; Mansfield et al. 2016). In terms of resilience factors, the present study focuses on strategies and personal resources, namely everyday behavior and affectivity, since they have been highlighted as important predictors of well-being and positive functioning.

\section{Mental Health Activities and Positive Mental Health}

Based on a Delphi consensus study, mental health activities were formulated as suggestions to reduce mental burdens and to treat mild depression (Morgan and Jorm 2009). The usefulness of mental health activities for reducing depressive symptoms has been confirmed empirically for individuals with sub-threshold depression (Morgan et al. 2012; Morgan et al. 2013). Moreover, practicing mental health activities offers the potential to facilitate positive emotions and to build individual resources, both of which are highly relevant for positive outcomes in work and life (Hobfoll 2002; Fredrickson 2001, 2004). Mental health activities can be grouped into three subscales, namely positive orientation, physical engagement, and emotion regulation (Hofmann and Kohlmann 2019a), all of which address important personal resources for mental health in general, and for teachers' well-being in particular (Mansfield et al. 2016). For example, the positive orientation subscale combines activities that can increase positive emotions (e.g., 'I do something I enjoy'), meaning in life (e.g., 'I remain in purposeful activities for at least a small part of the day'), self-efficacy (e.g., 'I am engaged in activities that give me a feeling of achievement'), and social connectivity (e.g., 'I have a trusted friend or relative, with whom I get out and do some activities'). Emotion regulation activities can reduce tension or arousal (e.g., 'I reward myself for reaching a small goal', 'I practice relaxation methods'), and physical engagement activities can enhance and maintain physical health (e.g., 'I am physically active or engaged in exercise', 'I eat a healthy and balanced diet'). We assume that mental health activities are positively related to positive mental health since mental health activities address individual resources known to be related to emotional, psychological, or social wellbeing (Bandura 1982; Berkman et al. 2000; Boehm and Kubzansky 2012; Fredrickson and Joiner 2002; King et al. 2006). 
Hypothesis 1: Mental health activities are positively associated with positive mental health.

\section{Mental Health Activities and Work-Related Behavior and Experiences}

Based on the idea that the combination of work motivation, coping abilities, and emotions is decisive for health-related statements and positive functioning within the work place, Schaarschmidt and Fischer (2008) formulated healthy and unhealthy types of work-related behavior and experiences: Healthy-ambitious (Type H), unambitious (Type U), excessively-ambitious (Type A), and risk of burnout (Type B, see Fig. 1).

The healthy-ambitious Type $\mathrm{H}$ reflects high, but not too high levels of work motivation and professional commitment combined with profound coping abilities and positive emotions. The unambitious Type $U$ reflects the type of protection with extremely low work motivation and professional commitment but a high resistance to stress, and generally positive emotions. Since Type U is more relevant from a motivational perspective than from a health perspective (Schaarschmidt and Fischer 2008), both Type $\mathrm{H}$ and Type $\mathrm{U}$ can be seen as healthy work-related behavior and experiences. On the contrary, Type A and Type B are considered at risk in regard to health (Schaarschmidt and Fischer 2008). Type A reflects excessive commitment in regard to work, combined with reduced abilities for emotional distancing and recovery, and a lack of positive emotions. Type B refers to the risk of burnout and is associated with diminished work motivation and professional commitment, a lack of coping abilities, and the lowest levels of work and life satisfaction. Generally, teachers assigned to Type A or Type B show reduced occupational well-being, high values of emotional exhaustion (Klusmann et al. 2008), and can be seen as at risk in regard to health (Bauer et al. 2006; Melamed et al. 2006; Schulz et al. 2011).

Earlier research indicates the potential of leisure time activities in order to cope with work-related challenges. Leisure time activities can balance work stressors and strains

\section{Type A (excessively-ambitious)}

- excessive work motivation and commitment

- reduced ability for emotional distancing and recovery

- lack of life satisfaction and support but high work satisfaction

Typ B (risk for Burnout)

- diminished work motivation and commitment

- lack of coping abilities

- lowest levels of work and life satisfaction, low experience of social support

\section{Type $\mathbf{H}$ (healthy-ambitious)}

- high, but not too high work motivation and commitment

- high resistance to stress and active coping

- high values in work and life satisfaction, high experience of support

\section{Type U (unambitious)}

- extremely low work motivation and commitment

- high resistance to stress but low values in active coping

- low values in work satisfaction but high levels of life satisfaction and experience of support

Fig. 1 Types of work-related behavior and experiences (based on Schaarschmidt and Fischer 2008) 
by increasing detachment from work, relaxation, mastery, and control (Sonnentag and Fritz 2007). Ten Brummelhuis and Bakker (2012) as well as Sonnentag and Zijlstra (2006) assessed the time engaged in leisure time activities and found that social activities, low effort activities, and physical activities enhanced psychological detachment and relaxation and reduced the need for recovery. Since psychological detachment and relaxation can be associated with good coping capacities, and the leisure time activities considered in these studies include aspects of mental health activities (e.g., social activities or physical activities), we assume that the practice of mental health activities is associated with high coping abilities. Hence, we expect mental health activities to be more a characteristic of those work-related behavior and experiences reflecting high coping abilities (Type $\mathrm{H}$ and Type $\mathrm{U}$ ) and less a characteristic of those types with low coping abilities (Type A and Type B).

Moreover, leisure time activities might also be relevant for work motivation. For example, engaging in positive leisure time activities (social, low effort, physical) increased vigor and engagement on the next work day (ten Brummelhuis and Bakker 2012). Likewise, personal resources (like self-efficacy) at T1 predicted work engagement at T2 (Ouweneel et al. 2011; Xanthopoulou et al. 2009). Since mental health activities can be related to important personal resources (e.g., self-efficacy, social support, meaning in life, and physical health), the engagement in mental health activities might also be connected to work-related motivation. Hence, we assume that engaging in mental health activities is particularly associated with Type $\mathrm{H}$, because unlike Type U, Type $\mathrm{H}$ reflects not only good coping abilities and positive emotions, but also high work motivation.

Hypothesis 2: The practice of mental health activities is a characteristic of both Type $\mathrm{H}$ and Type $\mathrm{U}$, but is particularly pronounced in Type $\mathrm{H}$.

On the contrary, a lower engagement in mental health activities is supposed to be especially prevalent in Type B, because this type reflects diminished work motivation, a lack of coping abilities, and negative emotions whereas Type A obtains high work motivation and work satisfaction. Hence, we assume that a lower engagement in mental health activities is especially a characteristic of Type B.

Hypothesis 3: A lower engagement in mental health activities is a characteristic of both Type A and Type B, but is particularly evident in Type B.

\section{Positive and Negative Affectivity, Mental Health Activities, and Positive Outcomes}

Empirical research on happiness and subjective well-being consistently discussed genetic set points that predispose individuals towards the experience of life satisfaction, positive affect, and negative affect (Diener et al. 2006; Lykken and Tellegen 1996; Tellegen et al. 1988). Although this set point was doubt into question (Diener et al. 2006) and is now more understood as a genetically determined range (Watson 2002), individual differences in the experience of positive and negative affect are highly relevant for positive outcomes in work and life (Diener 1984; Folkman 2008; Fredrickson 2004; Judge et al. 2017; Layous et al. 2014; Lyubomirsky et al. 2005). 
These individual differences are called positive affectivity (PA) and negative affectivity (NA; Watson et al. 1988). High PA describes the tendency to experience high active positive emotions (e.g., excited, enthusiastic) and thus, pleasurable engagement, whereas low PA refers to the experience of lethargy and sadness. High NA describes the tendency to experience high active negative emotions (e.g., angry, upset) and thus, unpleasurable engagement, whereas low NA describes the tendency to feel calm and relaxed (Watson et al. 1988). Since high PA refers to high active positive emotions whereas low NA addresses low active positive emotions, we consider both the presence of high trait PA and the absence of high trait NA as individual tendencies to experience positive emotions (Feldman-Barrett and Russel 1998, 1999; Tellegen et al. 1999). Empirical findings consistently associate both high PA and low NA with mental and physical health (Lyubomirsky et al. 2005; Pressman and Cohen 2005), overall job satisfaction (e.g., Connolly and Viswesvaran 2000; Judge and Larsen 2001; Judge et al. 2017), positive workplace experiences, and work behavior (Ng and Sorensen 2009). Thus, high trait PA and low trait NA can be seen as individual resources that influence relevant outcomes in work and life. Hobfoll (2002) argues that individual resources do not exist in isolation but instead will cumulate, leading to more resources over time. Likewise, Fredrickson assumes an upward spiral towards mental health and well-being based on the experience of positive emotions. Fredrickson argues that positive emotions broaden the individual's thought-action repertoire and improve motivation and coping (B\&B theory, Fredrickson 2001, 2004). This process does not only promote well-being in the moment but also impacts future coping abilities, because positive emotions increase the urge to engage in activities that build physical, intellectual, and social resources (Fredrickson 2004; Fredrickson 2013; Fredrickson and Joiner 2002). Even if positive emotions fade, resources such as a supportive environment, self-efficacy, or physical health will remain and strengthen future coping abilities, ultimately leading to increased psychological resilience and well-being (Fredrickson and Joiner 2002; Garland et al. 2010). Hence, high trait PA and low trait NA can be seen as personal resources that affect positive outcomes (such as positive mental health and healthy work-related behavior and experiences) both directly and indirectly via their influence on behavior that build long lasting resources (e.g., mental health activities).

Indeed, in addition to their direct effect, PA and NA seem to be also indirectly associated with desirable outcomes via their influence on specific behaviors (Diener et al. 1999; Lyubomirsky et al. 2005). Generally, high PA is associated with approaching behavior whereas high NA is related to withdrawal tendencies (Watson and Clark 1984; Watson et al. 1999). Moreover, positive emotions are assumed to increase the practice and maintenance of positive health behaviors (Fredrickson 2013) because they are both the source and the reward for goal-directed behavior (Rusting 1999; Seo et al. 2004; Watson et al. 1999). In line with that assumption, meta-analytic findings show that the tendency to experience positive emotions (high PA or low NA) precedes positive behaviors like social, leisure, professional, and physical activities. (Lyubomirsky et al. 2005). For example, higher state and trait PA is associated with a higher intake of dietary zinc, more exercise, and improved sleep (Kekäläinen et al. 2019; Ong et al. 2017; Pressman and Cohen 2005; Pressman et al. 2017). Considering 
these findings and both the COR theory (Hobfoll 2002) and the B\&B theory (Fredrickson 2004), we assume that high trait PA and low trait NA reflect individual resources that enhance the practice of mental health activities. In addition, we expect that mental health activities function as mediators between affectivity and desired outcomes in work and life (Layous et al. 2014).

Hypothesis 4: Mental health activities mediate the relationships between affectivity and positive mental health.

Hypothesis 5: Mental health activities mediate the relationships between affectivity and types of work-related behavior and experiences.

\section{The Present Study}

The present study extends prior research on everyday activities by assessing the practice of activities formulated to prevent mental burdens (mental health activities) and identifying their relationships with positive outcomes in work (healthy and unhealthy work-related behavior and experiences) and in life (positive mental health) in a sample of teachers. The aim of this study is twofold. First, identifying associations between mental health activities and teachers' well-being and positive functioning. We assume that the practice of mental health activities is associated with more positive mental health, and healthy work-related behavior and experiences, and with less unhealthy work-related behavior and experiences $(H 1-H 3)$. Second, testing the mediating role of mental health activities in the relationship between affectivity and relevant outcomes. We assume that mental health activities mediate the relationships between affectivity and relevant outcomes and thus, constitute an important path in the upward spiral dynamic of positive emotions and individual resources ( $\mathrm{H} 4$ and H5). This approach extends existing knowledge on mental health activities by evaluating their potential for the work context and providing a more detailed picture of the relationships between affectivity, mental health activities, and positive outcomes in teachers' work and life.

\section{Method}

\section{Sample and Procedure}

The sample of this study consisted of teachers $(n=326,75 \%$ female, age: $M=44$, $S D=11.85)$. The aims of the study were addressed at an annual Elementary School Teacher Conference in Germany in 2015. At this conference, practicing teachers meet and discuss current developments in their profession. Each individual received information on the aims of the study, on their voluntary participation as well confidentiality and anonymity. Participation in this study was not rewarded by any benefits. The study was online-based and a link was presented at the conference. Additionally, a link with relevant information was shared via e-mail to contacts of the authors who are working in the teaching profession. Via snow-ball sampling procedure, the link was shared with other teachers. 


\section{Measures}

All instruments regarded in this study are self-report instruments.

\section{Mental Health Activities}

The general practice of mental health activities (Morgan and Jorm 2009) was assessed with the Mental Health Activity Scale (MHAS, Hofmann and Kohlmann 2019a). The scale consist of three subscales: Positive orientation (four items: I do something I enjoy; I remain involved in purposeful activities for at least a small part of the day; I have a mental list of strategies that have worked in the past for depressive moods and use them; and I am engaged in activities that give me a feeling of achievement), physical engagement (three items: I am physically active or engaged in exercise; I practice a good sleep hygiene; and I eat a healthy and balanced diet), and emotion regulation (four items: I have a trusted friend or relative, with whom I get out and do some activities; I reward myself for reaching a small goal; I practice relaxation methods; and I talk over problems or feelings with someone who is supportive and caring). Within the MHAS total scale, all of these items were included, together with the item ' $I$ leave the house daily', which cannot be assigned to one of the three subscales. Individuals were told to state, how true the statement was for them in general. The response format ranged from 'not true' (1), 'barely true' (2), 'somewhat true' (3), to 'true' (4). The scale obtains acceptable reliability values (Hofmann and Kohlmann 2019a).

\section{Positive Mental Health}

Positive mental health was assessed with the Positive Mental Health Scale (PMH, Lukat et al. 2016). This scale combines the hedonic as well as the eudaimonic aspect of positive mental health (Keyes 2007) and assesses the presence of general emotional, psychological, and social well-being. The PMH-scale consists of nine statements (e.g., I am a calm, balanced human being; I manage well to fulfill my needs), the matching of which should be rated on a four point scale $(1=$ not true, $4=$ true $)$. The scale possesses a high internal consistency across different samples and an acceptable retest-reliability (Lukat et al. 2016).

\section{Work-Related Behavior and Experiences}

Healthy and unhealthy work-related behavior and experiences were assessed with the Work-Related Coping Behavior and Experience Pattern (WCEP) Questionnaire (Schaarschmidt and Fischer 2008). Earlier research indicates both the high internal consistency of the questionnaire and the validity of the four patterns (Rath et al. 2015; Schaarschmidt and Fischer 2008; Schulz et al. 2011). In this study, the short version with a total of 44 items and a five point unipolar scale (from $1=$ totally disagree, to $5=$ totally agree) was used. The instrument captures three work-related dimensions, namely professional commitment, coping capacity, and emotions by eleven subscales: subjective significance of work, professional ambition, tendency to exert, striving for 
perfection, emotional distancing, resignation tendencies, active coping, balance and mental stability, sense of achievement at work, life satisfaction, and experience of social support. Based on these subscales, the similarities of every participant to each of the four different WCEP types can be calculated using discriminant functions. These similarities are reflected in probability scores for each of the four WCEP types, where higher values indicate a higher accordance to the respective WCEP type (Schaarschmidt and Fischer 2008; syntax available from Pearson Assessment).

\section{Positive and Negative Affectivity}

Positive and negative affectivity were assessed with the German version of the PANAS scales (Krohne et al. 1996). The extent of PA (e.g., active, alert) and NA (e.g., nervous, jittery) is captured with ten items per scale. Individuals were asked to rate how they felt in general on a five point scale from 'very slightly or not at all' (1) to 'extremely' (5). The scale obtains good reliability as well as factorial and external validity (Watson et al. 1988; Krohne et al. 1996).

\section{Data Analysis}

Means, standard deviations, and internal consistencies were calculated for each applied variable, except for the probability scores for WCEP types. We found variations of normal distribution for the probability scores for WCEP types and missing values for gender and positive mental health. Hence, in order to determine the associations between WCEP types and mental health activities, we used Kendall's tau (Arndt et al. 1999). All the other correlation coefficients were calculated based on Pearson. To test whether mental health activities mediate the effect of affectivity on positive mental health and work-related behavior and experiences, we calculated mediation analyses with a Robust Maximum Likelihood Estimator (MLR) and Full Information Maximum Likelihood Procedure (FIML) using the $\mathrm{R}$ package lavaan (Rosseel 2012). This method allows using all available information and is robust against violations of normal distribution (Enders 2001; Graham 2009). PA and NA were set as predictors, mental health activities as mediators, and positive mental health and probability scores for WCEP types as dependent variables. In order to test $H 6$ and $H 7$, mediation analyses were calculated with the MHAS total scale. To explore associations of mental health activities in more detail, additional mediation analyses were calculated with the MHAS subscales. Figure 2 illustrates the hypothesized model.

All variables included in the analyses were z-standardized, since standardizing reduces the problem of multicollinearity among the included variables and makes it easier to interpret the results (Frazier et al. 2004). The direct effects of PA and NA on the dependent variables (without controlling for mental health activities) are represented by $c$. The direct effects of affectivity on the mediator are denoted $a$, whereas the effect of mental health activities on the dependent variable is denoted $b$. The strength of a mediation is found by multiplying $a \times b$. The direct relations between affectivity and the dependent variable when the mediator is included are denoted $c^{\prime}$. For all models, we allowed covariance between PA and NA. In the models with the MHAS subscales as mediators, covariance is also allowed between the subscales. 


\begin{tabular}{|c|cc|}
\hline $\begin{array}{c}\text { Positive } \\
\text { Affectivity }\end{array}$ & $c_{1}$ & Outcome \\
\cline { 1 - 1 } $\begin{array}{c}\text { Negative } \\
\text { Affectivity }\end{array}$ & $c_{2}$ & Outcome \\
\cline { 1 - 2 }
\end{tabular}

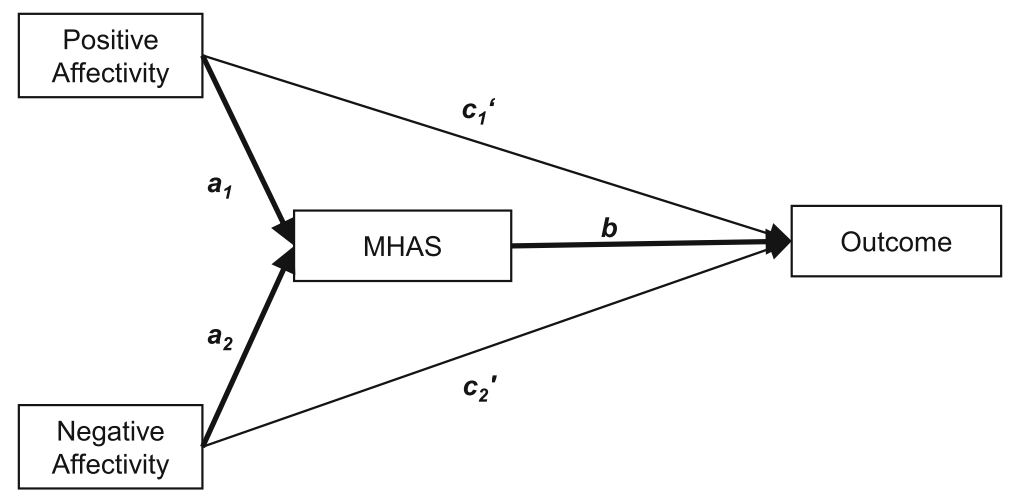

Fig. 2 Mediation pathways in the present study. Separate analyses were conducted with positive mental health or probability scores for WCEP types as outcome variables. The $c$ coefficients represent the total relationship between predictors and outcome variable (not controlling for mental health activities). The $c$ ' coefficients represent the strength of the association between predictor and outcome variable after controlling for the mediated pathway. Paths $a$ and $b$ represent the indirect paths including mental health activities

\section{Results}

\section{Correlations}

Intercorrelations and reliability estimates are displayed in Table 1.

As expected, mental health activities were strongly positively associated with PA and positive mental health. This was also true for the MHAS subscales, with positive orientation showing the highest correlation coefficients, followed by emotion regulation, and physical engagement.

In regard to work-related variables, mental health activities were positively associated with a higher probability for those WCEP types that reflect healthy work-related behavior and experiences, especially with Type H. All subscales were strongly positive related to a higher probability for Type $\mathrm{H}$, particularly the subscales positive orientation and emotion regulation. A higher probability for Type $U$ was positively associated with the subscales positive orientation and physical engagement only. A higher engagement in mental health activities was also associated with lower probabilities for both risk types, but particularly for Type B. All MHAS subscales were negatively related to the probability for Type B, whereas the probability for Type A was negatively associated with the subscales positive orientation and physical engagement only. Generally, positive orientation and physical engagement activities were associated with all WCEP types, whereas emotion regulation activities were associated with a higher probability for Type $\mathrm{H}$ and a lower probability for Type B only. 


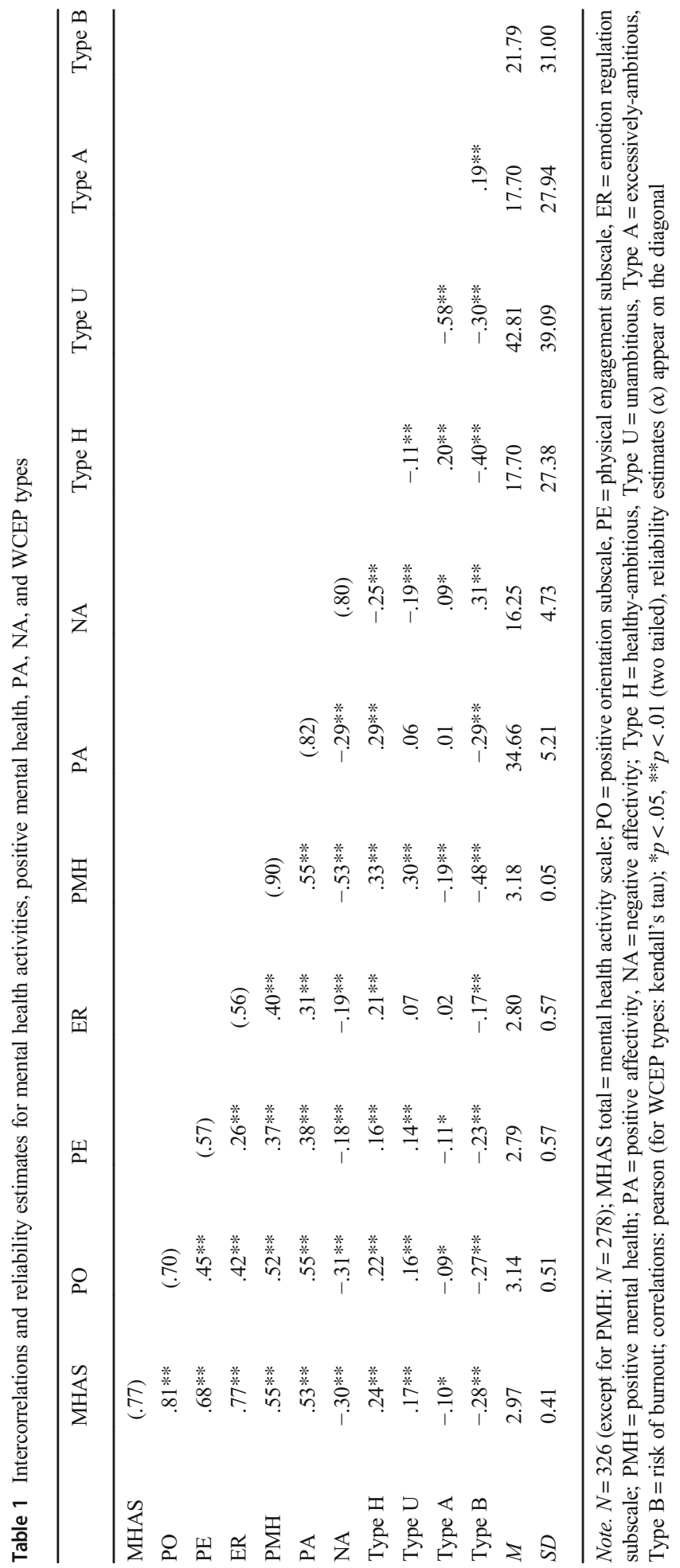




\section{Mediation Analyses}

Even after considering affectivity, mental health activities were significantly related to positive mental health and work-related behavior and experiences and mediated the relationship between affectivity and the respective outcomes. This was true for all models, except for the association between affectivity and the probability for Type $\mathrm{H}$.

Mental health activities partially mediated the effects of PA $(a \times b=.14, z=4.87$, $p<.001)$ and NA $(a \times b=-.05, z=-2.75, p<.01)$ on positive mental health (see Fig. 3). A detailed look at the subscales showed that positive orientation partially mediated the effects of both PA $(a 1 \times b 1=.08, z=2.69, p<.01)$ and NA $(a 4$ $\times b 1=-.03, z=-2.14, p<.05)$, whereas emotion regulation was a partial mediator for PA $(a 3 \times b 3=.04, z=2.41, p<.05)$ but not for NA $(a 6 \times b 3=-.02, z=-1.63, p=.10)$. Physical engagement was not a mediator, neither for PA $(a 2 \times b 2=.03, z=1.39$, $p=.17)$ nor for NA $(a 5 \times b 2=-.01, z=-0.89, p=.37$, see Fig. 4).

Mental health activities were also relevant mediators in regard to work-related behavior and experiences, except for the healthy-ambitious Type $\mathrm{H}$ (Table 2). For all the other probabilities, mental health activities were an important mediator, especially in regard to PA. For example, PA showed no direct association with the probabilities for Type U or Type A but was associated with these work-related behavior and experiences via a higher engagement in mental health activities. Moreover, PA was negatively associated with the probability for Type B and this relationship reduced

\begin{tabular}{|c|c|c|}
\hline Positive & $c_{1}=. \mathbf{4 3} * * *$ & $\begin{array}{c}\text { Positive Mental } \\
\text { Health }\end{array}$ \\
\cline { 3 - 3 } Affectivity & & $\begin{array}{c}\text { Positive Mental } \\
\text { Health }\end{array}$ \\
\hline Negative & $c_{2}=-. \mathbf{4 0} * * *$ & \\
Affectivity & &
\end{tabular}

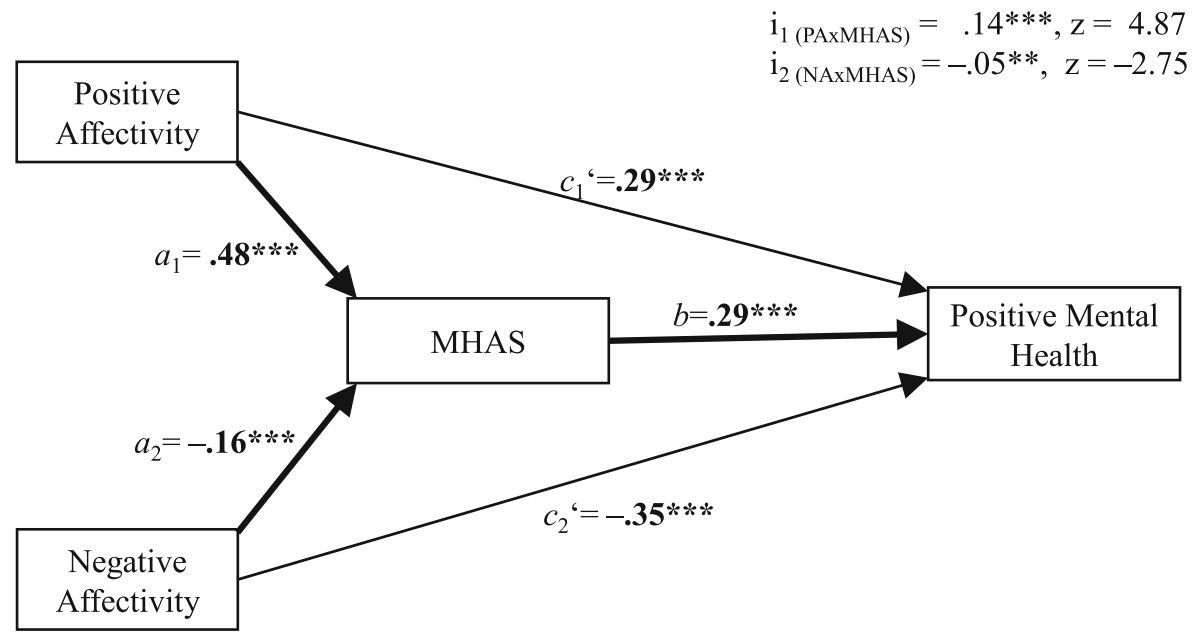

Fig. 3 Standardized path coefficients for positive and negative affectivity as the predictors of positive mental health, including paths to represent mediation by the mental health activities $\left(R^{2}=.50\right)$. Covariance between positive and negative affectivity was allowed $(-.29, p=.001)$ 


\begin{tabular}{|c|c|c|}
\hline Positive Affectivity & $c_{1}=. \mathbf{4 3} * * *$ \\
\cline { 3 - 4 } & \multicolumn{1}{c|}{ Positive Mental Health } \\
\hline Negative Affectivity & $c_{2}=-. \mathbf{4 0} * * *$ & Positive Mental Health \\
\hline
\end{tabular}

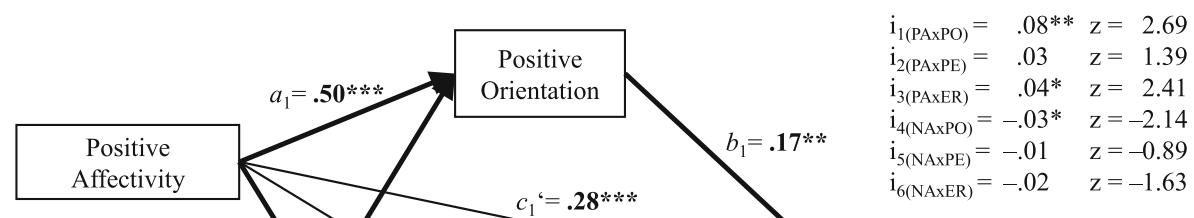

Fig. 4 Standardized path coefficients for positive and negative affectivity as the predictors of positive mental health, including paths to represent mediation by the three mental health activity subscales positive orientation, physical engagement, and emotion regulation $\left(R^{2}=.50\right)$. Covariance between positive and negative affectivity $(-.29, p<.01)$ and mediators (positive orientation and physical engagement $(.30, p<.001)$, positive orientation and emotion regulation $(.30, p<.001)$, physical engagement and emotion regulation $(.15, p<.01))$ was allowed

Table 2 PA and NA as predictors of work-related behavior and experiences with the path to represent mediation by mental health activities

Trait predictor Total effect of traits $c$ Direct effect of trait $c$ ' Mediation by mental $z$-values Total $R^{2}$ health activities

$a \quad b \quad a \times b$

Healthy-ambitious Type $\mathrm{H}$

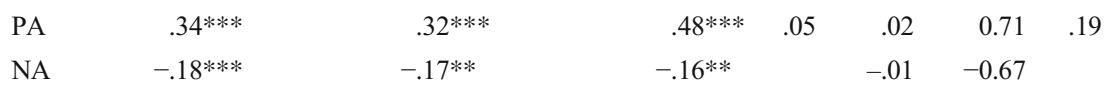

Unambitious Type U

$\begin{array}{llllllll}\text { PA } & .01 & -.09 & .48 * * * & .21 * * & .10 * * & 3.01 & .08 \\ \text { NA } & -.22 * * & -.18^{* *} & -.16^{* *} & & -.03 * & -2.30 & \end{array}$

Excessively-ambitious Type A

$\begin{array}{lrrrrrrr}\text { PA } & -.00 & .07 & .48 * * * & -.15^{*} & -.07 * & -2.01 & .03 \\ \text { NA } & .11 & .08 & -.16^{* *} & & .02 & 1.68 & \end{array}$

Risk of burnout Type B

\begin{tabular}{|c|c|c|c|c|c|c|}
\hline PA & $-.32 * * *$ & $-.23 * * *$ & $.48 * * *$ & $-.17 * *$ & $-.08 * *$ & -2.77 \\
\hline NA & $.34 * * *$ & $.31 * * *$ & $-.16 * *$ & & $.03 *$ & 2.05 \\
\hline
\end{tabular}

Note. $N=326$; standardized coefficients are reported; $c=$ direct effect of predictor on dependent variable, $c^{\prime}=$ direct effect of predictor with mediators included, $a=$ direct effects of predictor on mediator, $b=$ direct effect of mediator on dependent variable, $a \times b=$ strength of mediaton 
from $c=-.32$ to $c^{\prime}=-.23(a \times b=-.08, z=-2.77, p<.01)$ after mental health activities were included in the model. Although to a lesser extent, mental health activities were also relevant in regard to NA. The association between NA and the probability for Type $\mathrm{B}$ reduced slightly from $c=.34$ to $c^{\prime}=.31$, with a significant mediation effect for mental health activities $(a \times b=.03, z=2.05, p<.05)$. Likewise, mental health activities mediated the relationship between NA and the probability for Type $\mathrm{U}(a \times b=$ $-.03, z=-2.30, p<.05)$.

Considering the three MHAS subscales, a different pattern emerged. Instead of the total scale, MHAS subscales were individually related only to the probabilities for Type A and Type U. Physical engagement was the only subscale negatively associated with the probability for Type A $(b=-.13, p<.05)$, but mediation pathways were not significant, neither for PA $\left(c=-.00, p=.94 ; c^{\prime}=.08, p=.28 ; a=.36, p<.001 ; a \times\right.$ $b=-.05, z=-1.96, p=.05)$ nor for NA ( $c=.08, p=.15, a=-.07, p=.18 ; a \times b=.01$, $z=1.06, p=.29$ ), although the indirect path from PA was close $(p=.05)$. In regard to the probability for Type U, we found significant mediation pathways. Again, PA was associated with a higher probability for Type $\mathrm{U}$ only via a higher engagement in positive orientation activities $(a=.50, p<.001 ; b=.15, p<.05 ; a \times b=.07, z=2.12$, $\left.p<.05 ; c=.01, p=.81 ; c^{\prime}=-.11, p=.10\right)$ and physical engagement activities $(a=.36$, $p<.001 ; b=.15, p<.01 ; a \times b=.05, z=2.33, p<.05)$. Although PA was also positively associated with emotion regulation activities $(a=.28, p<.001)$, the engagement in these activities was not associated with a higher probability for Type $\mathrm{U}(b=-.02$, $p=.74)$ and thus not a significant mediator $(a \times b=-.01, z=-0.33, p=.74)$. All the other associations between MHAS subscales and probabilities for WCEP types were not significant.

\section{Discussion}

\section{Correlations of Mental Health Activities}

The first aim of this study was to test the relevance of mental health activities for teachers' well-being and positive functioning. We assumed that the practice of mental health activities is associated with more positive mental health and more healthy workrelated behavior and experiences. The results supported these assumptions. Practicing more mental health activities was associated with more positive mental health $(H 1)$ and higher probabilities for Type $\mathrm{H}$ and Type $\mathrm{U}(\mathrm{H} 2)$, both reflecting healthy work-related behavior and experiences. Negative associations of mental health activities were found with probabilities for those WCEP types that reflect unhealthy work-related behavior and experiences (Type A and Type B, H3). This is in line with our assumptions since the common feature of Type $\mathrm{H}$ and Type $\mathrm{U}$ are high coping abilities and positive emotions whereas the opposite is true for Type A and Type B. Hence, mental health activities seem to be associated with high coping abilities and positive emotions. Moreover, mental health activities seem to be also slightly related to work motivation and engagement, which is suggested by the size of correlations with probabilities for specific WCEP types. For example, the positive correlation coefficients of mental health activities are higher with the probability for Type $\mathrm{H}$ (high work motivation) than with the probability for Type $\mathrm{U}$ (low work motivation), which is in line with $H 2$. 
Supporting $H 3$, both the probability for Type A and the probability for Type B are negatively related to mental health activities but the coefficients are lower for Type A (high work motivation) than for Type B (low work motivation). Overall, mental health activities are associated with teachers' well-being and positive functioning and thus, seem to be a suitable combination of resilience strategies that could be recommended as preventive strategies with a particularly low-threshold (Grund et al. 2016; Kazdin and Rabbitt 2013; Mansfield et al. 2016). Generally, mental health activities seem to be more closely related to positive emotions and coping abilities than to work motivation. To enhance teacher motivation, it might therefore be helpful to integrate further strategies (e.g., meaningful goal setting, professional learning) and to strengthen contextual resources (e.g., recognition from others, positive school culture; Falecki and Mann 2020; Mansfield et al. 2016).

\section{Mental Health Activities as Mediators}

The second aim of this study was to test the mediating role of mental health activities in the relationship between affectivity and relevant outcomes. Based on earlier studies (Tkach and Lyubomirsky 2006; Warner and Vroman 2011) and both the COR theory (Hobfoll 2002) and the B\&B theory (Fredrickson 2004), we assumed that mental health activities functioned as mediators between dispositions and relevant outcomes. The results partly supported these assumptions. Mental health activities partly explained the relationships between both PA and NA and positive mental health (H4). Teachers high in PA were more likely to engage in mental health activities, which to some extent explained why PA was positively related to positive mental health. On the contrary, individuals high in NA were less likely to engage in mental health activities, which in turn was negatively related to positive mental health. Thus, not engaging in mental health activities partly explained why NA was associated with reduced positive mental health. This is in line with the B\&B theory (Fredrickson 2004) and the COR theory (Hobfoll 2002) as the tendency to experience positive emotions (either high PA or low NA) is associated with a higher engagement in activities that build other resources (e.g., self-efficacy, meaning in life, social support), which in turn are related to more positive mental health.

Our results also indicate that mental health activities are relevant for the work context. Interestingly, mental health activities were associated only with probabilities for those WCEP types that were not related to PA. For example, especially PA had a strong direct relation to the probability for Type $\mathrm{H}$ and engaging in mental health activities could not explain more than affectivity. In contrast, mental health activities, but not PA, were associated with a higher probability for Type $U$ and a lower probability for Type A. ${ }^{1}$ The finding that mental health activities are positively associated with the probability for Type $U$ (low in work motivation) and negatively

\footnotetext{
${ }^{1} \mathrm{PA}$ is associated not only with good coping abilities, higher work and life satisfaction, and more social support (Lyubomirsky et al. 2005), but also with high motivation (Ng and Sorensen 2009; Seo et al. 2004). However, both Type U and Type A are high only in one or two of these variables but low in the others. Type $\mathrm{U}$ reflects high coping capacity and life satisfaction but a lack of work motivation and work satisfaction, whereas the opposite is true for Type A. This might explain why PA is not directly associated with either the probability for Type U or for Type A. However, our results highlight that PA is indirectly associated with these types via a higher engagement in mental health activities.
} 
with the probability for Type A (high in work motivation) even after considering affectivity indicates, that instead of PA, mental health activities address primarily good coping capacities and positive emotions (high for Type U, low for Type A), and to a lesser extent work motivation.

In regard to Type $\mathrm{B}$, mental health activities had an additional exploratory value and mediated the associations between affectivity and the probability for Type B. Hence, not engaging in mental health activities seems to address different aspects in Type B than a lack of PA or the presence of NA. Moreover, not engaging in mental health activities partly explained why PA was negatively related to the probability for Type B and also why NA was positively associated to the probability for Type B, although to a lesser extent. This finding relates to the loss cycle proposed within the COR theory (Hobfoll 2002), where a lack of a personal resource (e.g., a lack of high PA or low NA) is not only worrisome per se but also leads to further resource loss (e.g., lack of selfefficacy, meaning) because of diminished resource gain (e.g., not engaging in mental health activities). Overall, $H 5$ was not supported for Type $H$, only in part supported for Type A and Type U, and fully supported in regard to Type B.

The engagement in mental health activities can partly explain the relationship between affectivity and teachers' positive mental health and, to a lesser extent, between affectivity and teachers' work-related behavior and experiences. These findings are comparable to research on happiness increasing activities (Tkach and Lyubomirsky 2006; Warner and Vroman 2011) and support the notion that the relevance of dispositions can in part be attributable to their effect on everyday activities (Diener et al. 1999; Lyubomirsky et al. 2005; McCrae and Costa 1991). We included affectivity and mental health activities in the model. Therefore the results also support the B\&B theory (Fredrickson 2004) and the COR theory (Hobfoll 2002), as they highlight the relevance of trait positive emotions for positive outcomes, both directly and indirectly via a higher engagement in activities with the potential to facilitate state positive emotions and to build individual resources. The gain cycle assumed of both the B\&B theory and the COR theory was reflected particularly in respect to positive mental health, while in relation to work-related behavior and experiences especially the loss cycle assumed within the COR theory became apparent. Hence, mental health activities might be useful to increase teachers' positive mental health and protect from work-related stress, but future research is needed in order to establish causal effects.

\section{Additional Findings}

A closer look at the MHAS subscales offered a deeper understanding of mental health activities. Engaging in mental health activities from any subscale was related to more positive mental health, a higher accordance to Type $\mathrm{H}$ and a lower accordance to Type $\mathrm{B}$, with the highest correlation coefficients for positive orientation. Thus, engaging in activities that aim to increase meaning, positive emotions, and self-efficacy, was strongly associated with positive mental health, high work motivation, good coping capacity, and positive emotions. Considering the COR theory (Hobfoll 2002), the subscale positive orientation addresses more resources (e.g., meaning, self-efficacy, positive emotions) than the physical engagement subscale (physical health) or the emotion regulation subscale (social support, relatedness). However, the highest correlation coefficients were found for the total scale. Hence, teachers that engage in a 
variety of mental health activities might accumulate a multitude of resources and might therefore be more capable of being motivated at work and cope with stressful situations (Falecki and Mann 2020; Hobfoll 2002; Mansfield et al. 2016).

In regard to mediation analyses, we found significant associations of the three MHAS subscales only in regard to Type A and Type U. After the consideration of affectivity, a higher engagement in physical engagement activities was significantly associated with a lower probability for Type A and a higher probability for Type U. A higher engagement in positive orientation activities was associated only with a higher probability for Type U. None of the MHAS subscales were significantly associated with the probability for Type B after affectivity was considered. Moreover, the coefficients were generally higher for the MHAS total scale than for MHAS subscales. This again suggests that especially the combination of all mental health activities is relevant, which would be in line with Sin and Lyubomirsky (2009). In their metaanalysis they found that engaging in a multitude of activities was more effective than focusing on only one activity. This could also apply to mental health activities. Engaging in various mental health activities seems to be more relevant for teachers' well-being and positive functioning than engaging in only a few specific activities, especially after considering affectivity.

Tkach and Lyubomirsky (2006) and Warner and Vroman (2011) found that everyday activities predicted happiness even after the consideration of dispositions. Likewise, we found that the relationships between mental health activities and positive mental health and mental health activities and certain work-related behavior and experiences persist, even after affectivity is taken into account. These findings suggest that engaging in mental health activities addresses not only hedonic aspects of positive mental health (emotional well-being), but also eudaimonic aspects (psychological and social wellbeing; Keyes 2007). A closer look at the subscales indicated that compared to physical engagement, especially positive orientation and emotion regulation activities seem to be related not only to hedonic but also to eudaimonic aspects of well-being as they were the only subscales that explained additional variance after consideration of affectivity. On the contrary, aspects like physical activity, a good sleep hygiene, and a healthy nutrition did not explain additional variance in positive mental health beyond affectivity and thus, seem to be more closely related to hedonic than to eudaimonic well-being. This assumption is in line with empirical findings on physical engagement activities and happiness. For example, Boehm and Kubzansky (2012) reviewed studies on positive psychological well-being and health behaviors and found that physical engagement activities were consistently associated with hedonic well-being, while relationships with eudaimonic well-being were inconsistent (Boehm and Kubzansky 2012).

\section{Limitations and Future Directions}

Even though the present study revealed promising results, important limitations have to be mentioned. First of all, the study was cross sectional and based on self-report measures only. Mental health activities were related to positive mental health and work-related behavior and experiences and, to some extent, explained the relationship between affectivity and the respective outcomes. However, conclusions about causality need to be addressed in longitudinal studies. Moreover, future studies could integrate other methods of assessment such as Experience Sampling methods. Also, more studies 
are needed to confirm the present results regarding the mediation effects of mental health activities. It may be possible that the power of the mediational tests was affected since the relationship between affectivity and mental health activities was stronger than the relationship between mental health activities and the outcome variables. If the predictor shows a stronger association with the mediator than the mediator with the outcome, it is more likely that the $b$ path is not significant (Frazier et al. 2004). Moreover, MHAS subscales obtained comparatively low reliability values, which overestimate the effect of the predictor and underestimate the effect of the mediator on the outcome variable (Frazier et al. 2004). Thus, future studies for replications are needed.

Furthermore, the sample was based on teachers only. The teaching profession constitutes a certain line of work with specific challenges. We found that engaging in mental health activities was associated with more positive mental health and less unhealthy work-related behavior and experiences. This suggests that mental health activities might balance these profession specific challenges. However, further research is needed to confirm this assumption and replicate the present findings on different samples and professions. It would also be interesting to explore the extent to which the present results in regard to positive mental health are applicable to other age groups, such as children, adolescents, or the elderly (Diener et al. 2006; Kessler and Staudinger 2009; Ryff and Keyes 1995).

We found that in contrast to positive orientation activities and physical engagement activities, emotion regulation activities might also be related to work motivation. It is possible that these activities are beneficial especially for those individuals that are highly engaged and emotionally involved with work. For those individuals, practicing emotion regulation activities might increase psychological detachment from work and thus, increase vigor and engagement on the next work day (ten Brummelhuis and Bakker 2012). Future studies are needed to investigate this assumption.

Furthermore, it seems possible that certain types of individuals benefit from specific activities more than others. Lyubomirsky and Layous (2013) highlighted this personactivity fit in their positive-activity model. According to this model, the perception of an activity such as exercising determines, if one can derive positive emotions from it. Thus, future studies could integrate the perception of a specific activity as well. Likewise, associations with personal resources, basic needs, as well as hedonic and eudaimonic aspects of well-being (Ryan and Deci 2000; Ryff and Keyes 1995) could be explored more deeply. Both Xanthopoulou et al. (2009) and Ouweneel et al. (2011) found a reciprocal relationship between positive emotions, personal resources, and study engagement. Yet unclear is if this reciprocal relationship can be found in regard to mental health activities as facilitators of positive emotions and personal resources as well. Can mental health activities increase state positive emotions and personal resources and thus, initiating an upward spiral proposed by the B\&B theory and the COR theory? In order to answer these questions, it is necessary to investigate the engagement in mental health activities on a daily basis, and assess state and trait positive and negative affect as well as individual resources longitudinally (comparable to Cohn et al. 2009). This would allow a more detailed understanding of their relationship and imply causality. Also, the time perspective might be interesting. How long does one need to engage in new mental health activities to achieve such possible effects? Clearly, more research is needed in this regard. 


\section{Conclusions and Practical Implications}

The present study integrated research of pathogenesis with salutogenesis. In a sample of teachers, we found that the practice of mental health activities was associated with more positive mental health and less unhealthy work related-behavior and experiences. Furthermore, mental health activities partly explained the relationship between affectivity and the respective outcomes and thus, constitute an important factor in the upward spiral dynamic of positive emotions and individual resources. These findings for teachers underline the potential of mental health activities as lifestyle suggestions for mental health promotion, within and beyond the work context (Barry and Friedli 2008). Practicing mental health activities might be a useful way to improve positive mental health and healthy work-related behavior and experiences, and the present results support the potential of mental health activities. Future studies are needed to determine causal effects and to extend the findings to other professions.

Acknowledgements The authors would like to thank Uwe Heim-Dreger and Heike Eschenbeck for their support in data collection.

Funding Open Access funding enabled and organized by Projekt DEAL. This research was supported by the University of Education Schwäbisch Gmünd.

\section{Compliance with Ethical Standards}

\section{Conflict of Interest None.}

Ethics Approval The study was approved by the Ethics Committee of the University of Education Schwäbisch Gmünd.

Open Access This article is licensed under a Creative Commons Attribution 4.0 International License, which permits use, sharing, adaptation, distribution and reproduction in any medium or format, as long as you give appropriate credit to the original author(s) and the source, provide a link to the Creative Commons licence, and indicate if changes were made. The images or other third party material in this article are included in the article's Creative Commons licence, unless indicated otherwise in a credit line to the material. If material is not included in the article's Creative Commons licence and your intended use is not permitted by statutory regulation or exceeds the permitted use, you will need to obtain permission directly from the copyright holder. To view a copy of this licence, visit http://creativecommons.org/licenses/by/4.0/.

\section{References}

Arndt, S., Turvey, C., \& Andreasen, N. C. (1999). Correlating and predicting psychiatric symptom ratings: Spearman's $r$ versus Kendall's tau correlation. Journal of Psychiatric Research, 33, 97-104.

Bandura, A. (1982). Self-efficacy mechanism in human agency. American Psychologist, 37(2), 122-147.

Barry, M. M., \& Friedli, L. (2008). The influence of social, demographic and physical factors on positive mental health in children, adults and older people (foresight mental capital and wellbeing project state-ofscience review: SR-B3). London. Government Office of Science and Innovation.

Berkman, L. F., Glass, T., Brissette, I., \& Seeman, T. E. (2000). From social integration to health: Durkeim in the new millenium. Social Science \& Medicine, 51, 843-857.

Bauer, J., Stamm, A., Virnich, K., Wissing, K., Müller, U., Wirsching, M., \& Schaarschmidt, U. (2006). Correlation between burnout syndrome and psychological and psychosomatic symptoms among teachers. 
International Archives of Occupational and Environmental Health, 79(3), 199-204. https://doi.org/10. 1007/s00420-005-0050-y.

Bauer, J., Unterbrink, T., Hack, A., Pfeifer, R., Buhl-Griesshaber, V., Müller, U., Wesche, H., Frommhold, M., Seibt, R., Scheuch, K., \& Wirsching, M. (2007). Working conditions, adverse events and mental health problems in a sample of 949 German teachers. International Archives of Occupational and Environmental Health, 80(5), 442-449. https://doi.org/10.1007/s00420-007-0170-7.

Boehm, J. K., \& Kubzansky, L. D. (2012). The heart's content: The association between positive psychological well-being and cardiovascular health. Psychological Bulletin, 138(4), 655-691. https://doi.org/10. 1037/a0027448.

Caunt, B. S., Franklin, J., Brodaty, N. E., \& Brodaty, H. (2013). Exploring the causes of subjective well-being: A content analysis of peoples' recipes for long-term happiness. Journal of Happiness Studies, 14(2), 475499. https://doi.org/10.1007/s10902-012-9339-1.

Cohn, M. A., Fredrickson, B. L., Brown, S. L., Mikels, J. A., \& Conway, A. M. (2009). Happiness unpacked: Positive emotions increase life satisfaction by building resilience. Emotion, 9(3), 361-368. https://doi.org/ 10.1037/a0015952.

Connolly, J. J., \& Viswesvaran, C. (2000). The role of affectivity in job satisfaction: A meta-analysis. Personality and Individual Differences, 29(2), 265-281. https://doi.org/10.1016/S0191-8869(99)00192-0.

Diener, E. (1984). Subjective well-being. Psychological Bulletin, 95, 542-575.

Diener, E., Lucas, R. E., \& Scollon, C. N. (2006). Beyond the hedonic treadmill: Revising the adaptation theory of well-being. The American Psychologist, 61(4), 305-314. https://doi.org/10.1037/0003-066X.61. 4.305.

Diener, E., Suh, E. M., Lucas, R. E., \& Smith, H. L. (1999). Subjective well-being: Three decades of Progress. Psychological Bulletin, 125(2), 276-302.

Enders, C. K. (2001). The performance of the full information maximum likelihood estimator in multiple regression models with missing data. Educational and Psychological Measurement, 61(5), 713-740. https://doi.org/10.1177/0013164401615001.

Falecki, D., \& Mann, E. (2020). Practical applications for building teacher wellbeing in education. In C. F. Mansfield (Ed.), Cultivating teacher resilience: International approaches, applications and impact (pp. 175-191). Singapore: Springer.

Feldman-Barrett, L., \& Russel, J. A. (1998). Independence and bipolarity in the structure of current affect. Journal of Personality and Social Psychology, 74(4), 967-984.

Feldman-Barrett, L., \& Russel, J. A. (1999). The structure of current affect: Controversies and emerging consensus. Current Direction in Psychological Science, 8(1), 10-14.

Folkman, S. (2008). The case for positive emotions in the stress process. Anxiety, Stress, and Coping, 21(1), 3-14. https://doi.org/10.1080/10615800701740457.

Frazier, P. A., Tix, A. P., \& Barron, K. E. (2004). Testing Moderator and Mediator Effects in Counseling Psychology Research. Journal of Counseling Psychology, 51(1), 115-134. https://doi.org/10.1037/00220167.51.1.115.

Fredrickson, B. L. (2001). The role of positive emotions in positive psychology: The broaden-and-build theory of positive emotions. American Psychologist, 56(3), 218-226.

Fredrickson, B. L. (2004). The broaden-and-build theory of positive emotions. Philosophical Transactions of the Royal Society of London. Series B, Biological Sciences, 359(1449), 1367-1378. https://doi.org/10. 1098/rstb.2004.1512.

Fredrickson, B. L. (2013). Positive emotions broaden and build. In P. Devine \& A. Plant (Eds.), Advances in Experimental Social Psychology (pp. 47:1-53). Amsterdam: Academic Press.

Fredrickson, B. L., \& Joiner, T. (2002). Positive emotions trigger upward spirals toward emotional well-being. Psychological Science, 13(2), 172-175. https://doi.org/10.1111/1467-9280.00431.

Garland, E. L., Fredrickson, B. L., Kring, A. M., Johnson, D. P., Meyer, P. S., \& Penn, D. L. (2010). Upward spirals of positive emotions counter downward spirals of negativity: Insights from the broaden-and-build theory and affective neuroscience on the treatment of emotion dysfunctions and deficits in psychopathology. Clinical Psychology Review, 30(7), 849-864. https://doi.org/10.1016/j.cpr.2010.03.002.

Gehrmann, A. (2013). Zufriedenheit trotz beruflicher Beanspruchungen? Anmerkungen zu den Befunden der Lehrerbelastungsforschung [Satisfaction despite professional demands?: Comments on the findings of teacher stress research]. In M. Rothland (Ed.), Belastung und Beanspruchung im Lehrerberuf: Modelle, Befunde, Interventionen (2nd ed., pp. 175-190). Springer Fachmedien Wiesbaden; Imprint: Springer VS.

Graham, J. W. (2009). Missing data analysis: Making it work in the real world. Annual Review of Psychology, 60, 549-576. https://doi.org/10.1146/annurev.psych.58.110405.085530.

Grund, A., Brassler, N. K., \& Fries, S. (2016). The long arm of work: A motivational conflict perspective on teacher strain. Teaching and Teacher Education, 60, 153-163. https://doi.org/10.1016/j.tate.2016.08.013. 
Harding, S., Morris, R., Gunnell, D., Ford, T., Hollingworth, W., Tilling, K., Evans, R., Bell, S., Grey, J., Brockman, R., Campbell, R., Araya, R., Murphy, S., \& Kidger, J. (2019). Is teachers' mental health and wellbeing associated with students' mental health and wellbeing? Journal of Affective Disorders, 242, 180-187. https://doi.org/10.1016/j.jad.2018.08.080.

Hobfoll, S. E. (1989). Conservation of resources: A new attempt at conceptualizing stress. American Psychologist, 44(3), 513-524.

Hobfoll, S. E. (2002). Social and psychological resources and adaptation. Review of General Psychology, 6(4), 307-324. https://doi.org/10.1037//1089-2680.6.4.307.

Hofmann, H., \& Kohlmann, C.-W. (2019a). Dimensionality of mental health activities in a German sample. Health Promotion International, 34(6), 1106-1116. https://doi.org/10.1093/heapro/day078.

Hofmann, H., \& Kohlmann, C.-W. (2019b). The role of positive and negative affectivity in healthy and unhealthy work-related behavior and experiences. European Journal of Health Psychology, 26(2), 56-67. https://doi.org/10.1027/2512-8442/a000030.

Hwang, Y.-S., Bartlett, B., Greben, M., \& Hand, K. (2017). A systematic review of mindfulness interventions for in-service teachers: A tool to enhance teacher wellbeing and performance. Teaching and Teacher Education, 64, 26-42. https://doi.org/10.1016/j.tate.2017.01.015.

Jorm, A. F. (2012). Mental health literacy: Empowering the community to take action for better mental health. The American Psychologist, 67(3), 231-243. https://doi.org/10.1037/a002595.

Judge, T. A., \& Larsen, R. J. (2001). Dispositional affect and job satisfaction: A review and theoretical extension. Organizational Behavior and Human Decision Processes, 86(1), 67-98. https://doi.org/10. 1006/obhd.2001.2973.

Judge, T. A., Weiss, H. M., Kammeyer-Mueller, J. D., \& Hulin, C. L. (2017). Job attitudes, job satisfaction, and job affect: A century of continuity and of change. The Journal of Applied Psychology, 102(3), 356374. https://doi.org/10.1037/ap10000181.

Kazdin, A. E., \& Rabbitt, S. M. (2013). Novel models for delivering mental health services and reducing the burdens of mental illness. Clinical Psychological Science, 1(2), 170-191. https://doi.org/10.1177/ 2167702612463566.

Kekäläinen, T., Freund, A. M., Sipilä, S., \& Kokko, K. (2019). Cross-sectional and longitudinal associations between leisure time physical activity, mental well-being and subjective health in middle adulthood. Applied Research in Quality of Life, 22(8), 171-1116. https://doi.org/10.1007/s11482-019-09721-4.

Kessler, E.-M., \& Staudinger, U. M. (2009). Affective experience in adulthood and old age: The role of affective arousal and perceived affect regulation. Psychology and Aging, 24(2), 349-362. https://doi.org/ $10.1037 / \mathrm{a} 0015352$.

Keyes, C. L. M. (2006). Subjective well-being in mental health and human development research worldwide: An introduction. Social Indicators Research, 77(1), 1-10. https://doi.org/10.1007/s11205-005-5550-3.

Keyes, C. L. M. (2007). Promoting and protecting mental health as flourishing: A complementary strategy for improving national mental health. The American Psychologist, 62(2), 95-108. https://doi.org/10.1037/ 0003-066X.62.2.95.

King, L. A., Hicks, J. A., Krull, J. L., \& Del Gaiso, A. K. (2006). Positive affect and the experience of meaning in life. Journal of Personality and Social Psychology, 90(1), 179-196. https://doi.org/10.1037/ 0022-3514.90.1.179.

Klusmann, U., Kunter, M., Trautwein, U., Lüdtke, O., \& Baumert, J. (2008). Teachers' occupational wellbeing and quality of instruction: The important role of self-regulatory patterns. Journal of Educational Psychology, 100(3), 702-715. https://doi.org/10.1037/0022-0663.100.3.702.

Klusmann, U., Richter, D., \& Lüdtke, O. (2016). Teachers' emotional exhaustion is negatively related to students' achievement: Evidence from a large-scale assessment study. Journal of Educational Psychology, 108(8), 1193-1203. https://doi.org/10.1037/edu0000125.

Krohne, H. W., Egloff, B., Kohlmann, C.-W., \& Tausch, A. (1996). Untersuchungen mit einer deutschen Version der "Positive und Negative Affect Schedule" (PANAS). Diagnostica, 42(2), 139-156.

Layous, K., Chancellor, J., \& Lyubomirsky, S. (2014). Positive activities as protective factors against mental health conditions. Journal of Abnormal Psychology, 123(1), 3-12. https://doi.org/10.1037/a0034709.

Lukat, J., Margraf, J., Lutz, R., van der Veld, W. M., \& Becker, E. S. (2016). Psychometric properties of the positive mental health scale (PMH-scale). BMC Psychology, 4(1), 8. https://doi.org/10.1186/s40359-0160111-x.

Lykken, D., \& Tellegen, A. (1996). Happiness is a stochastic phenomenon. Psychological Science, 7(3), 186189.

Lyubomirsky, S., King, L., \& Diener, E. (2005). The benefits of frequent positive affect: Does happiness lead to success? Psychological Bulletin, 131(6), 803-855. https://doi.org/10.1037/0033-2909.131.6.803. 
Lyubomirsky, S., \& Layous, K. (2013). How do simple positive activities increase well-being? Current Directions in Psychological Science, 22(1), 57-62. https://doi.org/10.1177/0963721412469809.

Mansfield, C. F. (Ed.). (2020). Cultivating teacher resilience: International approaches, applications and impact. Singapore: Springer.

Mansfield, C. F., Beltman, S., Broadley, T., \& Weatherby-Fell, N. (2016). Building resilience in teacher education: An evidenced informed framework. Teaching and Teacher Education, 54, 77-87. https://doi. org/10.1016/j.tate.2015.11.016.

McCrae, R. R., \& Costa, P. T. (1991). Adding liebe und arbeit: The full five-factor models and well-being. Personality and Social Psychology Bulletin, 17(2), 227-232.

Melamed, S., Shirom, A., Toker, S., Berliner, S., \& Shapira, I. (2006). Burnout and risk of cardiovascular disease: Evidence, possible causal paths, and promising research directions. Psychological Bulletin, 132(3), 327-353. https://doi.org/10.1037/0033-2909.132.3.327.

Montgomery, C., \& Rupp, A. A. (2005). A meta-analysis for exploring the diverse causes and effects of stress in teachers. Canadian Journal of Education, 28(3), 458. https://doi.org/10.2307/4126479.

Morgan, A. J., \& Jorm, A. F. (2009). Self-help strategies that are helpful for sub-threshold depression: A Delphi consensus study. Journal of Affective Disorders, 115(1-2), 196-200. https://doi.org/10.1016/j.jad. 2008.08.004.

Morgan, A. J., Jorm, A. F., \& Mackinnon, A. J. (2012). Email-based promotion of self-help for subthreshold depression: Mood memos randomised controlled trial. The British Journal of Psychiatry: the Journal of Mental Science, 200(5), 412-418. https://doi.org/10.1192/bjp.bp.111.101394.

Morgan, A. J., Mackinnon, A. J., \& Jorm, A. F. (2013). Behavior change through automated e-mails: Mediation analysis of self-help strategy use for depressive symptoms. Behaviour Research and Therapy, 51(2), 57-62. https://doi.org/10.1016/j.brat.2012.11.002.

Ng, T. W., \& Sorensen, K. L. (2009). Dispositional affectivity and work-related outcomes: A meta-analysis. Journal of Applied Social Psychology, 39(6), 1255-1287. https://doi.org/10.1111/j.1559-1816.2009. 00481.x.

Ong, A. D., Kim, S., Young, S., \& Steptoe, A. (2017). Positive affect and sleep: A systematic review. Sleep Medicine Reviews, 35, 21-32. https://doi.org/10.1016/j.smrv.2016.07.006.

Ouweneel, E., Le Blanc, P. M., \& Schaufeli, W. B. (2011). Flourishing students: A longitudinal study on positive emotions, personal resources, and study engagement. The Journal of Positive Psychology, 6(2), 142-153. https://doi.org/10.1080/17439760.2011.558847.

Philipp, A., \& Kunter, M. (2013). How do teachers spend their time? A study on teachers' strategies of selection, optimisation, and compensation over their career cycle. Teaching and Teacher Education, 35, 1-12. https://doi.org/10.1016/j.tate.2013.04.014.

Pressman, S. D., \& Cohen, S. (2005). Does positive affect influence health? Psychological Bulletin, 131(6), 925-971. https://doi.org/10.1037/0033-2909.131.6.925.

Pressman, S. D., Jenkins, B. N., Kraft-Feil, T. L., Rasmussen, H., \& Scheier, M. F. (2017). The whole is not the sum of its parts: Specific types of positive affect influence sleep differentially. Emotion, 17(5), 778793. https://doi.org/10.1037/emo0000256.

Rath, H. M., Steimann, M., Ullrich, A., Rotsch, M., Zurborn, K.-H., Koch, U., et al. (2015). Psychometric properties of the Occupational Stress and Coping Inventory (AVEM) in a cancer population. Acta Oncologica, 54(2), 232-242. https://doi.org/10.3109/0284186X.2014.933873.

Rosseel, Y. (2012). Lavaan: An R package for structural equation modeling. Journal of Statistical Software, 48(2), 1-36. https://doi.org/10.18637/jss.v048.i02.

Rothland, M. (2013). Beruf: Lehrer/Lehrerin - Arbeitsplatz: Schule: Charakteristika der Arbeitstätigkeit und Bedingungen der Berufssituation [teacher occupation - School as workplace: Job characteristics and conditions of the professional situation]. In M. Rothland (Ed.), Belastung und Beanspruchung im Lehrerberuf: Modelle, Befunde, Interventionen (2nd ed., pp. 21-39). Wiesbaden: Springer Fachmedien Wiesbaden; Imprint: Springer VS.

Rusting, C. L. (1999). Interactive effects of personality and mood on emotion-congruent memory and judgment. Journal of Personality and Social Psychology, 77(5), 1073-1086.

Ryan, R. M., \& Deci, E. L. (2000). Self-determination theory and the facilitation of intrinsic motivation, social development, and well-being. American Psychologist, 55(1), 68-78.

Ryff, C. D., \& Keyes, C. L. M. (1995). The structure of psychological well-being revised. Journal of Personality and Social Psychology, 69(4), 719-727.

Schaarschmidt, U., \& Fischer, A. W. (2008). AVEM - Arbeitsbezogenes Verhaltens- und Erlebensmuster [AVEM - work-related behavior and experience pattern]: Manual (3rd ed.). Frankfurt am Main: Pearson. 
Schult, J., Münzer-Schrobildgen, M., \& Sparfeldt, J. R. (2014). Belastet, aber hochzufrieden? [burdened, but highly satisfied?]. Zeitschrift Für Gesundheitspsychologie, 22(2), 61-67. https://doi.org/10.1026/0943$8149 / \mathrm{a} 000114$.

Schulz, M., Damkröger, A., Voltmer, E., Löwe, B., Driessen, M., Ward, M., \& Wingenfeld, K. (2011). Workrelated behaviour and experience pattern in nurses: Impact on physical and mental health. Journal of Psychiatric and Mental Health Nursing, 18(5), 411-417. https://doi.org/10.1111/j.1365-2850.2011. 01691.x.

Seo, M.-G., Feldman Barrett, L., \& Bartunek, J. M. (2004). The role of affective experience in work motivation. Academy of Management Review, 29(3), 423-439. https://doi.org/10.5465/amr.2004. 13670972.

Sin, N. L., \& Lyubomirsky, S. (2009). Enhancing well-being and alleviating depressive symptoms with positive psychology interventions: A practice-friendly meta-analysis. Journal of Clinical Psychology, 65(5), 467-487. https://doi.org/10.1002/jclp.20593.

Sonnentag, S., \& Fritz, C. (2007). The recovery experience questionnaire: Development and validation of a measure for assessing recuperation and unwinding from work. Journal of Occupational Health Psychology, 12(3), 204-221. https://doi.org/10.1037/1076-8998.12.3.204.

Sonnentag, S., \& Zijlstra, F. R. H. (2006). Job characteristics and off-job activities as predictors of need for recovery, well-being, and fatigue. Journal of Applied Psychology, 91(2), 330-350. https://doi.org/10. 1037/0021-9010.91.2.330.

Spilt, J. L., Koomen, H. M. Y., \& Thijs, J. T. (2011). Teacher wellbeing: The importance of teacher-student relationships. Educational Psychology Review, 23(4), 457-477. https://doi.org/10.1007/s10648-0119170-y.

Tellegen, A., Lykken, D. T., Bouchard, T. J., Wilcox, K. J., Segal, N. L., \& Rich, S. (1988). Personality similarity in twins reared apart and together. Journal of Personality and Social Psychology, 54(6), 10311039.

Tellegen, A., Watson, D., \& Clark, L. A. (1999). On the dimensional and hierachical structure of affect. Psychological Science, 10(4), 297-303.

ten Brummelhuis, L. L., \& Bakker, A. B. (2012). Staying engaged during the week: The effect of off-job activities on next day work engagement. Journal of Occupational Health Psychology, 17(4), 445-455. https://doi.org/10.1037/a0029213.

Tkach, C., \& Lyubomirsky, S. (2006). How do people pursue happiness? Relating personality, happinessincreasing strategies, and well-being. Journal of Happiness Studies, 7(2), 183-225. https://doi.org/10. 1007/s10902-005-4754-1.

Walsh, R. (2011). Lifestyle and mental health. American Psychologist, 66(7), 579-592. https://doi.org/10. $1037 / \mathrm{a} 0021769$.

Warner, R. M., \& Vroman, K. G. (2011). Happiness inducing behaviors in everyday life: An empirical assessment of "the how of happiness". Journal of Happiness Studies, 12(6), 1063-1082. https://doi.org/ 10.1007/s10902-010-9245-3.

Watson, D. (2002). Positive affectivity: The disposition to experience pleasurable emotional states. In C. R. Synder \& S. J. Lopez (Eds.), Handbook of Positive Psychology (pp. 106-119). Oxford: Oxford University Press.

Watson, D., \& Clark, L. A. (1984). Negative affectivity: The disposition to experience aversive emotional states. Psychological Bulletin, 96(3), 465-490.

Watson, D., Clark, L. A., \& Tellegen, A. (1988). Development and validation of brief measures of positive and negative affect: The PANAS scales. Journal of Personality and Social Psychology, 54(6), 10631070.

Watson, D., Wiese, D., Vaidya, J., \& Tellegen, A. (1999). The two general activation systems of affect: Structural findings, evolutionary considerations, and psychological evidence. Journal of Personality and Social Psychology, 76(5), 820-838.

Xanthopoulou, D., Bakker, A. B., Demerouti, E., \& Schaufeli, W. B. (2009). Reciprocal relationships between job resources, personal resources, and work engagement. Journal of Vocational Behavior, 74(3), 235244. https://doi.org/10.1016/j.jvb.2008.11.003.

Publisher's Note Springer Nature remains neutral with regard to jurisdictional claims in published maps and institutional affiliations. 